\title{
Barrier protective use of skin care to prevent chemotherapy-induced cutaneous symptoms and to maintain quality of life in patients with breast cancer
}

\author{
This article was published in the following Dove Press journal: \\ Breast Cancer:Targets and Therapy \\ I August 2014 \\ Number of times this article has been viewed
}

\section{Johannes Wohlrab' \\ Nikola Bangemann ${ }^{2}$ \\ Anke Kleine-Tebbe ${ }^{3}$ \\ Marc Thill 4,5 \\ Sherko Kümmel ${ }^{6}$ \\ Eva-Maria Grischke ${ }^{7}$ \\ Rainer Richter ${ }^{8}$ \\ Sophie Seite 9 \\ Diana Lüftner ${ }^{10}$}

'Martin Luther University Halle-

Wittenberg, Department of Dermatology

and Venereology, Halle (Saale),

Interdisciplinary Breast Centre, University

Hospital Charité Berlin, Campus Benjamin

Franklin, Berlin, Germany, ${ }^{3}$ Breast Centre

DRK Hospital, Berlin, ${ }^{4}$ Breast Centre

University of Lübeck, Department of

Gynaecology and Obstetrics, Lübeck,

${ }^{5}$ Department of Gynaecology and

Obstetrics, Agaplesion Markus Hospital,

Frankfurt am Main, ${ }^{6}$ Breast Centre and

Clinic of Senology, Hospital Essen-Mitte,

Essen, ${ }^{7}$ Breast Centre University of

Tübingen, Department of Gynaecology,

Tübingen, ${ }^{8}$ L'Oréal, Deutschland

$\mathrm{GmbH}$, Düsseldorf, 'La Roche-Posay,

Dermatological Laboratories, Asnières,

France; ${ }^{10}$ University Hospital Charité Berlin,

Campus Benjamin Franklin, Department

of Hematology, Oncology and Tumour

Immunology, Berlin, Germany

Correspondence: Johannes Wohlrab Department of Dermatology and Venereology, Martin Luther University Halle-Wittenberg, Ernst-Grube-Straße 40; D-06097 Halle (Saale), Germany Tel +493455573933

Fax +49 3455573944

Email johannes.wohlrab@medizin.unihalle.de
Purpose: Chemotherapy with anthracyclines, taxanes, or alkylating agents often causes cutaneous side effects. Nonspecific inhibition of the proliferative activity of keratinocytes has antidifferentiation effects that lead to defects in the barrier function and, thus, to dry, itchy, and irritable skin. These cutaneous symptoms reduce the quality of life of the patients considerably. Conditioning with topical application of niacinamide uses the cytoprotective and barrier stabilizing effect of vitamin $\mathrm{B}_{3}$.

Patients and methods: A multicenter randomized crossover study investigated the influence of the test preparation on the quality of life compared to standard care for 73 patients with breast cancer undergoing adjuvant or neoadjuvant cytostatic therapy. Primary target parameter was the Dermatology Life Quality Index with its respective subscales after 6 weeks of a twice-daily application of the respective preparations. Additionally, specific symptoms such as pruritus, dryness, and irritability have been assessed using visual analog scales.

Results: Regarding the total score of the Dermatology Life Quality Index, no relevant differences could be observed. However, the results for the "symptoms and feelings" subscale show a significant advantage in favor of the test preparation. Significant superiority of the test preparation could also be observed in the secondary target parameters, the visual analog scales $(P<0.05)$.

Conclusion: The results show for the first time a significant superiority of prophylactic application of niacinamide for maintaining quality of life while undergoing cytostatic treatment.

Keywords: supportive therapy, niacinamide, chemotherapy, anthracycline, taxane

\section{Introduction}

The prevalence of cancers in industrial nations is steadily increasing. ${ }^{1}$ With approximately 75,000 new cases each year, breast cancer is a common tumor in Germany and by far the most frequent malignant tumor in women. ${ }^{2}$ Based on guidelines, therapeutic regimens are chosen depending on clinical grading, hormone receptor state, lymph node involving, and the patient's age. For intermediate and high-risk conditions, this almost always involves adjuvant systemic chemotherapy. ${ }^{3}$ Usually, combinations of cytostatics are used, sometimes together with targeted therapies. Depending on dosage schedule, treatment period, and the type of combination, therapies show considerable unwanted side effects. Additionally, the severe psychological stress for patients with cancer as well as its social impact has to be taken into account. ${ }^{4}$ Therefore, more and more supportive measures are validated in oncology. ${ }^{5-7}$ 
Unwanted side effects affecting the skin organ are mostly non-life-threatening, but can seriously reduce patients' quality of life and, thus, endanger therapeutic success by reducing compliance. ${ }^{8}$ From a dermatological point of view, various clinical patterns can be determined; these occur quite frequently and, therefore, have a high practical relevance. ${ }^{9,10}$ Recommendations for the therapeutical management for some of these patterns exist, the evidence of which is worked on progressively. ${ }^{11,12}$ Recommendations for prophylactic measures, on the other hand, have not gone beyond general notes on care so far. ${ }^{13-15}$

However, the success of specific prophylactic strategies depends very much on the pathomechanism of individual reaction patterns, and these are not necessarily specific to substances or their combinations. ${ }^{16}$ Also, it is important to distinguish between toxic and nontoxic reactions. Unspecific cytotoxic effects on the epithelium or skin appendages caused by the cytostatics themselves or by their metabolites are the most common events and can be observed in up to $30 \%$ of all cancer patients, regardless of the type of the primary tumor, but dependent on the regimen and the combination of chemotherapy. Furthermore, individual pathologic factors such as pharmacogenetics, comorbidities, concomitant medication, sweating, cutaneous vulnerability, and genetic disposition seem to be important. On the whole rather rare, but quite frequent in connection with targeted therapies, specific antiproliferative effects can be observed. The intrinsic tyrosine kinase activity of the epidermal growth factor and its receptors on the cell surface (EGFR) play a major role here. ${ }^{17}$ The specific blockade of EGFR by therapeutic antibodies as well as the unspecific inhibition by multikinase inhibitors can cause alterations associated primarily with skin appendages (acne-like rash, paronychia). ${ }^{9}{ }^{18-22}$ Elimination of cytostatics and their metabolites by eccrine sweat can cause both direct toxic effects due to accumulation in the stratum corneum, especially in palmar and plantar skin, and inflammatory phenomena due to depletion of the antioxidative capacity of the skin (chemotherapy-induced acral erythema, also known as palmar-plantar erythrodysesthesia or hand-foot syndrome). ${ }^{11}$

Most frequently, however, barrier disorders caused by complex dysfunction of proliferation and differentiation of interfollicular keratinocytes and epidermal stem cells can be observed. Clinical symptoms are dryness and scaling of the skin, which after latency can lead to inflammatory irritations along with pruritus and, therefore, scratching. ${ }^{23} \mathrm{Up}$ to now, only individual recommendations for supportive skin care, aiming at barrier substitution, can be found in literature. ${ }^{16}$ These recommendations are based on concepts that have been established for chronic inflammatory skin diseases with endogenous barrier deficiency (eg, atopic dermatitis) and have been empirically applied to oncological situations. Here, the different pathomechanism of barrier dysfunction under therapy with cytostatics is ignored, and proactive use is propagated without scientific evidence. ${ }^{16}$ The clinical use of a niacinamide-containing preparation implements the concept of using the well-known effects of the natural vitamin proactively to prevent clinically relevant chemotherapy-induced barrier dysfunction. ${ }^{24-28}$ The advantages of niacinamide are its anti-inflammatory effects due to inhibition of proinflammatory factors, as well as its ability to increase the expression of serine palmitoyltransferase as the key enzyme for ceramide synthesis. ${ }^{29-33}$ Even after repeated epicutaneous application of preparations with $4 \%$ niacinamide, no systemic toxic effects or interactions with other systemically applied active substances are to be expected. ${ }^{34}$

A study complying with the principles of Good Clinical Practice investigated the clinical benefits of the proactive use of a semisolid niacinamide-containing preparation in patients with breast cancer undergoing cytostatic therapy.

\section{Patients and methods Study objective and study design}

The objective of this multicenter prospective randomized reference-controlled crossover study was to validate the clinical relevance of the preventive use of a niacinamidecontaining barrier-protective preparation under real life conditions in patients undergoing cytostatic therapy. Female patients aged 18 years or older and diagnosed with breast cancer were enrolled in the study on condition that they had an indication for adjuvant or neoadjuvant chemotherapy with anthracyclines or taxanes; combination with trastuzumab was allowed. Not enrolled were patients who: had clinical signs of a barrier dysfunction before study start; had indications for an atopic or psoriatic disposition in their medical history; or were using pharmaceutical or over-the-counter products that have vasoactive, anti-inflammatory, or diuretic effects, or those that affect the lipid metabolism. Study start was the first day patients received chemotherapy. One study group first used the test preparation (TP) for 6 weeks and, subsequently, standard care (SC) for 6 weeks. The other study group first used SC for 6 weeks and, subsequently, TP for 6 weeks. The Dermatology Life Quality Index (DLQI) as primary target parameter was recorded over the time of 12 weeks. ${ }^{35-38}$ In addition to the total DLQI score, the six DLQI subscales were included in the analysis (Figure S1). ${ }^{39,40}$ As second target parameters, the symptoms pruritus, dryness, and irritability were quantified and recorded via visual analog scales. ${ }^{41}$ 


\section{Test preparation}

TP was a lipophilic cream containing $4 \%$ niacinamide, shea butter as lipophilic, and thermal spring water from La Roche-Posay as hydrophilic phase (Lipikar ${ }^{\circledR}$ Baume AP, La Roche-Posay Laboratoire Pharmaceutique, La Roche-Posay, France). TP was applied twice daily on the whole body. Standard care (SC), which was defined as the patients usual body care in their individual quantity and frequency, was chosen as control arm.

\section{Statistics}

The confirmative evaluation of the principal target parameter was done by analysis of variance. All other parameters were evaluated descriptively. The number of the values, missing values, mean value, standard deviation, median, quartile, minimum, and maximum were specified for all continuous values. For all other values, frequency tables were generated. The statistical evaluation was carried out using the SAS package version 9.1 (SAS Institute Inc., Cary NC, USA).

\section{Ethics}

The study was approved by the Ethics Committee of the Faculty of Medicine Charité, Humboldt University Berlin; the respective ethics committees of the study sites agreed with this approval. All patients gave their written informed consent to their participation in this study. The study was conducted according to the guidelines of Good Clinical Practice.

\section{Results}

\section{Patient characteristics}

The study was conducted between February 2012 and April 2013 in six breast cancer centers in Germany. A total of 95 patients aged between 25 and 77 years were enrolled (Figure 1). Via block randomization, 46 patients were randomized in group TP/SC and 48 in group SC/TP. Twenty-one patients dropped out before the end of the study and one patient had to be excluded for protocol deviation. A total of 73 patients were included in the analysis.

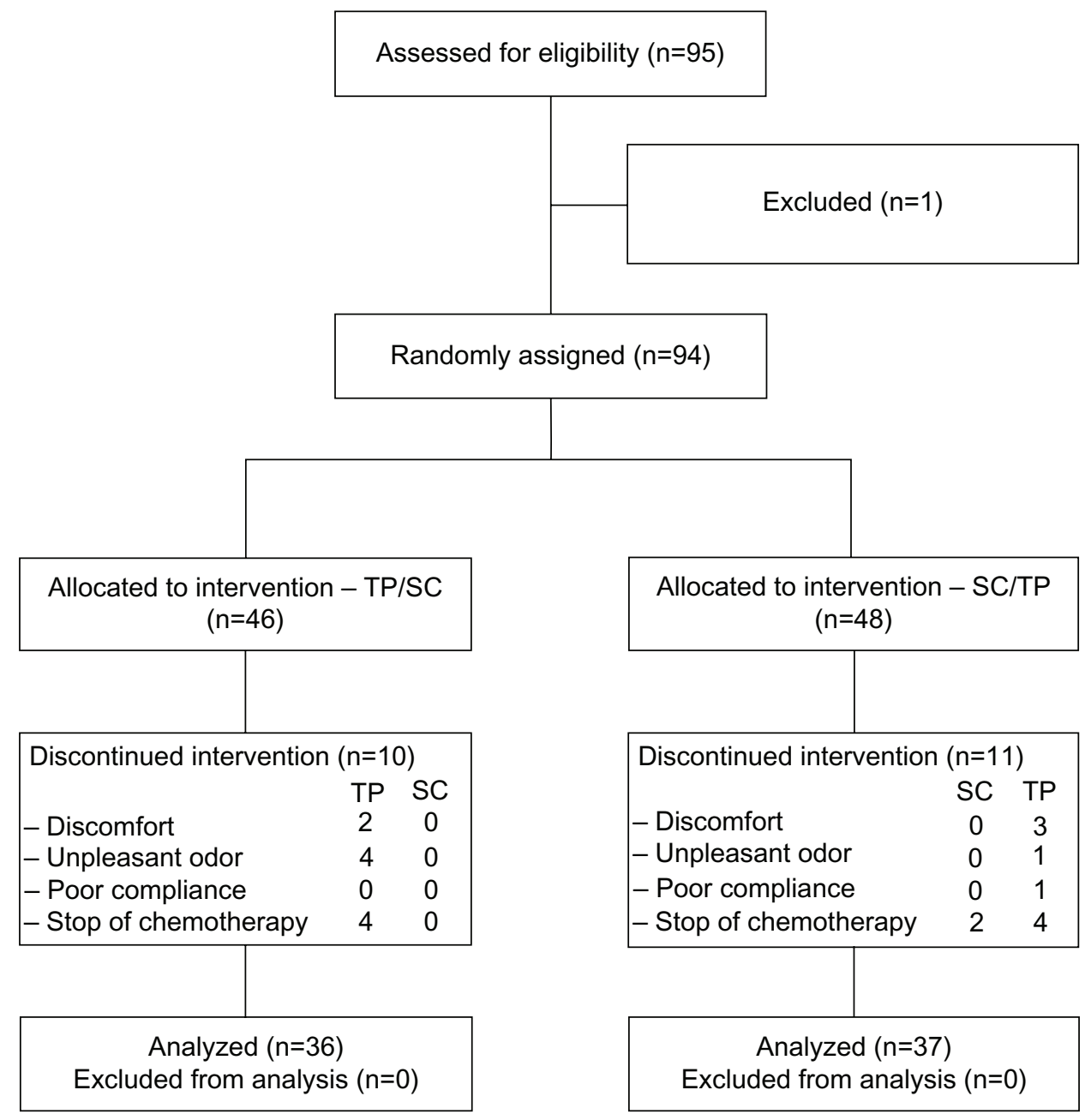

Figure I CONSORT diagram.

Abbreviations: SC, standard care; SC/TP, patient group that starts with SC followed by TP; TP, test preparation; TP/SC, patient group that starts with TP followed by SC; CONSORT, Consolidated Standards of Reporting Trials. 


\section{Treatment details}

The most frequent chemotherapies received by patients were: epirubicin plus cyclophosphamide plus docetaxel or paclitaxel; cyclophosphamide plus epirubicin plus 5-fluorouracil; and doxorubicin plus cyclophosphamide plus docetaxel, sometimes combined with trastuzumab. The respective regimens and their frequencies are shown in Table 1. The study had no influence on the therapeutic decision.

\section{DLQI results}

Comparing the total DLQI score between TP and SC after 6 weeks did not show any significant differences (Figure 2A). However, the analysis of the six subscales showed significant superiority of TP for the "symptoms and feelings" aspect after week 4. After crossover, superiority of TP can be observed after week 8 (Figure 2B). For the other subscales,

Table I Characteristics of study population

\begin{tabular}{|c|c|c|c|c|c|c|}
\hline \multirow[t]{2}{*}{ Characteristics } & \multicolumn{2}{|c|}{$\begin{array}{l}\text { Group } \\
\text { TP/SC }\end{array}$} & \multicolumn{2}{|c|}{$\begin{array}{l}\text { Group } \\
\text { SC/TP }\end{array}$} & \multicolumn{2}{|c|}{ Total } \\
\hline & $\mathbf{n}$ & $\%$ & $\mathbf{n}$ & $\%$ & $\mathbf{n}$ & $\%$ \\
\hline Total & 36 & 49 & 37 & 51 & 73 & 100 \\
\hline \multicolumn{7}{|l|}{ Age, years } \\
\hline$<30$ & 1 & 1.37 & 0 & 0.00 & I & 1.37 \\
\hline $30-40$ & I & 1.37 & 5 & 6.85 & 6 & 8.22 \\
\hline $4 I-50$ & 11 & 15.07 & 13 & $|7.8|$ & 24 & 32.88 \\
\hline $51-60$ & 9 & 12.33 & 12 & 16.44 & 21 & 28.77 \\
\hline $6 I-70$ & 10 & 13.70 & 5 & 6.85 & 15 & 20.55 \\
\hline $7 I-80$ & 4 & 5.48 & 2 & 2.74 & 6 & 8.22 \\
\hline Mean & 6.0 & 8.2 & 6.2 & 8.4 & 12.2 & 16.7 \\
\hline SD & 4.2 & 5.7 & 4.8 & 6.6 & 8.4 & 11.6 \\
\hline \multicolumn{7}{|l|}{ Chemotherapy } \\
\hline $4 \times \mathrm{EC}, 4 \times \mathrm{Doc}$ & 3 & 4.11 & 2 & 2.74 & 5 & 6.85 \\
\hline $\begin{array}{l}4 \times \mathrm{EC}, 4 \times \text { Doc, } \\
\text { Trastuzumab }\end{array}$ & 1 & 1.37 & 0 & 0.00 & I & 1.37 \\
\hline $3 \times \mathrm{FEC}, 3 \times \mathrm{Doc}$ & 6 & 8.22 & 8 & 10.96 & 14 & 19.18 \\
\hline $\begin{array}{l}3 \times \text { FEC, } 3 \times \text { Doc, } \\
\text { Trastuzumab }\end{array}$ & 0 & 0.00 & 2 & 2.74 & 2 & 2.74 \\
\hline $6 \times \mathrm{TAC}$ & 4 & 5.48 & 5 & 6.85 & 9 & 12.33 \\
\hline $4 \times \mathrm{EC}, 12 \times \mathrm{Pac}$ & 13 & 17.81 & 8 & 10.96 & 21 & 28.77 \\
\hline $\begin{array}{l}4 \times \mathrm{EC}, 12 \times \mathrm{Pac}, \\
\text { Trastuzumab }\end{array}$ & 5 & 6.85 & 5 & 6.85 & 10 & 13.70 \\
\hline $4 \times \mathrm{FEC}$ & 0 & 0.00 & 1 & 1.37 & 1 & 1.37 \\
\hline $6 \times \mathrm{FEC}$ & 1 & 1.37 & 3 & 4.11 & 4 & 5.48 \\
\hline $6 \times \mathrm{TCbH}$ & I & 1.37 & 1 & 1.37 & 2 & 2.74 \\
\hline $18 \times \mathrm{Pac}+\mathrm{Dox}$ & 0 & 0.00 & 2 & 2.74 & 2 & 2.74 \\
\hline $4 \times \mathrm{TC}$ & 1 & 1.37 & 0 & 0.00 & I & 1.37 \\
\hline Unknown & 0 & 0.00 & I & 1.37 & I & 1.37 \\
\hline
\end{tabular}

Abbreviations: Doc, docetaxel; Dox, doxorubicin; EC, epirubicin plus cyclophosphamide; FEC, 5-fluorouracil plus epirubicin plus cyclophosphamide; Pac, paclitaxel; SC, standard care; SC/TP, patient group that starts with SC followed by TP; SD, standard deviation; TAC, doxorubicin plus cyclophosphamide plus docetaxel; $\mathrm{TC}$, taxane plus carboplatin; $\mathrm{TCbH}$, taxane plus carboplatin plus trastuzumab; TP, test preparation; TP/SC, patient group that starts with TP followed by SC. no significant differences could be found. The visual analog scale values for the secondary target parameters of pruritus, dryness, and irritability show significant superiority for TP after 6 weeks (Figure 3A-C).

\section{Discussion}

The need for supportive therapy in oncology is obvious and widely acknowledged. ${ }^{5}$ Supportive measures depend on the underlying condition, the stage of the disease, the treatment regimen, as well as on individual pathologic and social factors. If possible, evidence based recommendations should be aspired to. From a dermatological point of view, a prophylactic or proactive approach must be distinguished from therapeutic or reactive strategies. Both strategies interact in the management of unwanted cutaneous reactions and have high practical relevance. Referring to safety data of published studies, the probability of pathogenetic cutaneous symptoms depending on dosage and combination of cytostatics can be estimated. The most common symptom, especially when using anthracyclines, taxanes, or alkylating agents, is dry and itchy skin as expression of complex dysfunctional differentiation. This becomes phenotypically relevant usually after 7-14 days. Substitution, specifically targeted to condition the barrier function, starting at the same time as cytostatic therapy can prevent, slow down, or reduce clinical symptoms. For this conditioning effect, niacinamide provides favorable preconditions. It has cytoprotective effects due to stimulation of DNA repair mechanisms. ${ }^{42,43}$ In addition, there are indications that niacinamide supports the release of cytostatics from cells, depending on concentration, and therefore reduces their antiproliferative effects. ${ }^{44}$ These effects of the topically applied and, therefore, only cutaneously bioavailable active substance are the basis for the hypothesis of a conditioning proactive use during cytostatic therapy. The above-mentioned additional effects concerning ceramide synthesis and anti-inflammation are cumulative. ${ }^{29,45,46}$

To recruit enough patients that met the inclusion and exclusion criteria in a timely manner, and to avoid seasonal influences, six breast centers were selected for competitive recruitment. The high cumulative dropout rate of $23 \%$ in this study is mainly due to discontinuation of chemotherapy for medical reasons. Additionally, some cases of early termination can be attributed to chemotherapy-induced alterations of sweat gland functions (hyperhidrosis) and the olfactory sense (dysosmia). The present study data and published data raise no safety concerns for clinical use. ${ }^{47-49}$ Furthermore, niacinamide has been used systemically as a perfusion enhancer for palliative care in patients with breast cancer due to its relaxant effects on vascular smooth muscle cells. ${ }^{50,51}$ 

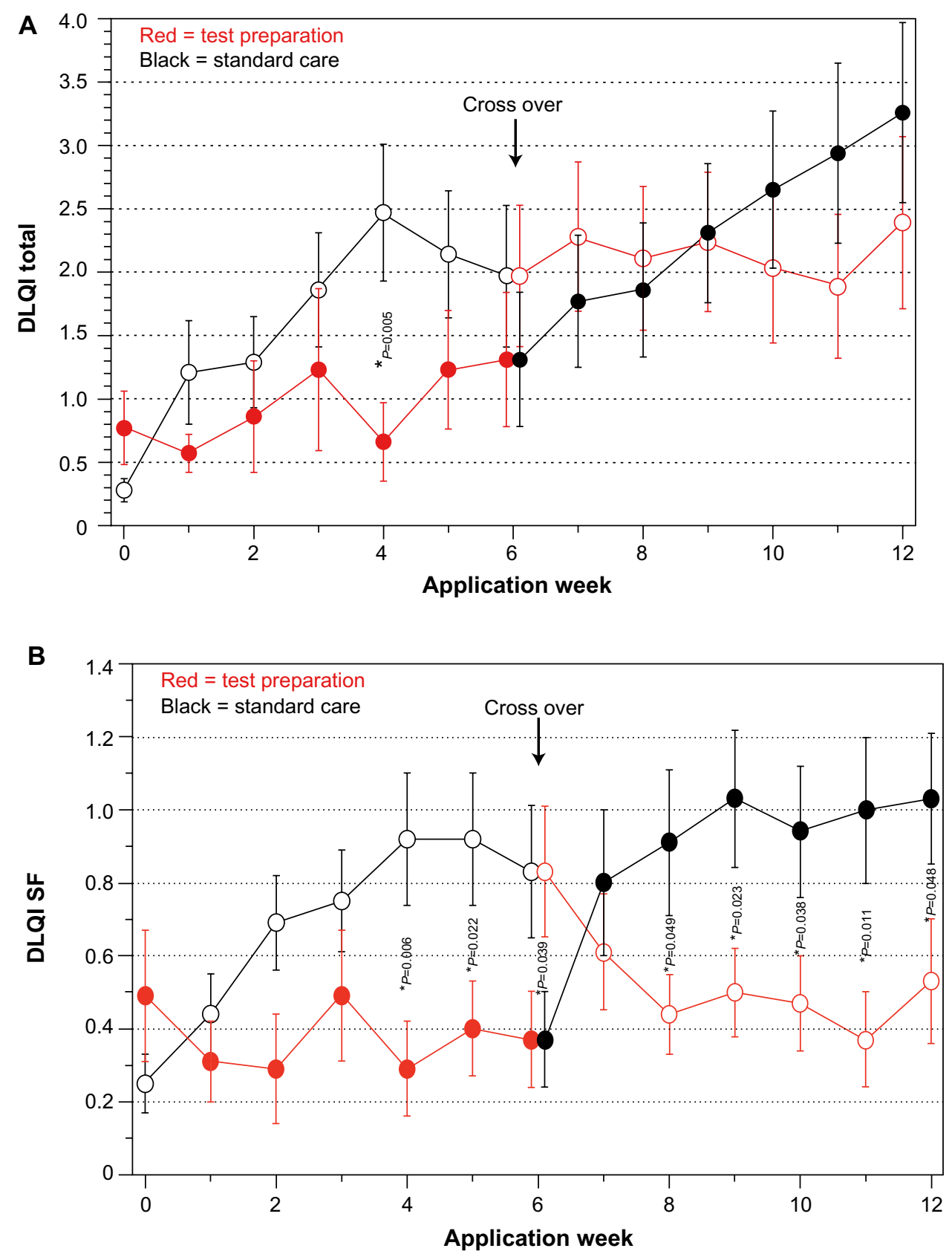

Figure 2 DLQI: comparison of both groups over application time.

Notes: (A) DLQI total, (B) DLQI SF. SC/TP group SC/TP group $n=48 ;$ TP/SC group $n=46$. *Statistical significant difference between the groups, analysis of variance ( $P \leq 0.05$ ). Abbreviations: DLQI, Dermatology Life Quality Index; ${ }^{35} \mathrm{SF}$, subscale Symptoms and Feelings.

The results of this study suggest that cytostatic cutaneous symptoms among other health problems have a negative impact on quality of life for the patients. That supports the usefulness of a proactive prophylactic skin care, which should be applied with the start of cytostatic therapy at the latest. Despite the psychological stress that accompanies the start of a cytostatic therapy, the patients experienced the offer of supportive skin care as motivating rather than as an additional burden. The superiority of TP over SC, regarding the mentioned aspect of quality of life and regarding pruritus, dryness, and irritability, proves the efficacy of TP for prophylactic use within the study setting. Statements regarding the efficacy of the preparation for other pathogenetic patterns of unwanted drug reactions, eg, palmar-plantar erythrodysesthesia, acne-like rash, or toxic exanthema, cannot be made. ${ }^{9,20,52-54}$ Also, no therapeutic effects can be propagated regarding established, inflammatory skin conditions. 

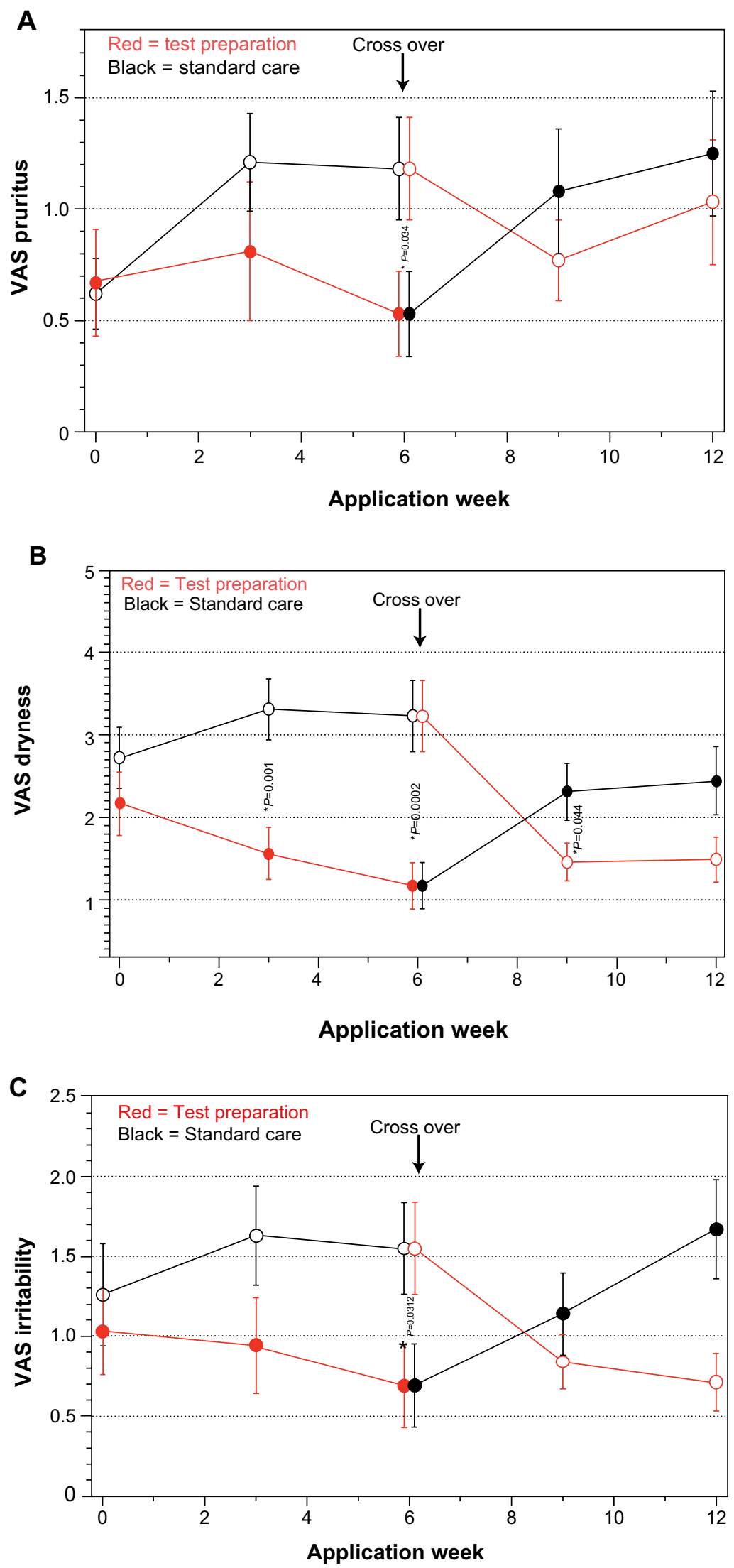

Figure 3 VAS: comparison of both groups over application time.

Notes: (A) Pruritus, (B) skin dryness, (C) irritability. Standard care/test preparation group $n=48$; test preparation/standard care group $n=46$. *Statistical significant difference between the groups, analysis of variance $(P \leq 0.05)$.

Abbreviation: VAS, visual analog scale. 


\section{Conclusion}

The results of this study favor the niacinamide-containing TP for proactive treatment accompanying cytostatic therapies with classic antiproliferative substances. Certainly, further investigations are necessary in order to strengthen the evidence for the supportive use of topical niacinamide in oncology.

\section{Acknowledgments}

The authors wish to thank Ms Andrea Stennett for excellent assistance in study management and Dr Gerd Franke for biometrical evaluation.

\section{Disclosure}

The study was fully sponsored by La Roche-Posay Laboratoire Dermatologique L'Oréal Deutschland GmbH GeorgGlock-Straße 1840474 Düsseldorf, Germany. J Wohlrab and D Lüftner received lecture fees, were co-operation partners in scientific projects and investigators in clinical studies sponsored by L'Oréal Deutschland GmbH. R Richter and S Seite are employed by the sponsor. The other authors were investigators in this clinical study sponsored by L'Oréal Deutschland GmbH and declare no conflict of interest.

\section{References}

1. Assi HA, Khoury KE, Dbouk H, Khalil LE, Mouhieddine TH, ElSaghirNS. Epidemiology and prognosis of breast cancer in young women. J Thorac Dis. 2013;5:S2-S8.

2. Thomssen C, Marschner N, Untch M, et al. ABC1 Consensus Conference - a German Perspective: First International Consensus Conference on Advanced Breast Cancer (ABC1), Lisbon, November 5 , 2011. Breast Care (Basel). 2012;7:52-59.

3. Truong PT, Olivotto IA, Whelan TJ, et al. Clinical practice guidelines for the care and treatment of breast cancer: 16. Locoregional postmastectomy radiotherapy. CMAJ. 2004;170:1263-1273.

4. Kroenke CH, Quesenberry C, Kwan ML, Sweeney C, Castillo A, Caan BJ. Social networks, social support, and burden in relationships, and mortality after breast cancer diagnosis in the Life After Breast Cancer Epidemiology (LACE) study. Breast Cancer Res Treat. 2013;137:261-271.

5. Petrie W, Logan J, DeGrasse C. Research review of the supportive care needs of spouses of women with breast cancer. Oncol Nurs Forum. 2001;28:1601-1607.

6. García-Estévez L, Tusquets I, Alvarez I, et al. Supportive care for patients with early breast cancer. Clin Transl Oncol. 2010;12:32-42.

7. Freedman O, Amir E, Zimmermann C, Clemons M. Filling in the gaps: reporting of concurrent supportive care therapies in breast cancer chemotherapy trials. Support Care Cancer. 2011;19:315-322.

8. Viale PH. Chemotherapy and cutaneous toxicities: implications for oncology nurses. Semin Oncol Nurs. 2006;22:144-151.

9. Gutzmer R, Wollenberg A, Ugurel S, Homey B, Ganser A, Kapp A. Cutaneous side effects of new antitumor drugs: clinical features and management. Dtsch Arztebl Int. 2012;109:133-140.

10. Hartmann JT, Haap M, Kopp HG, Lipp HP. Tyrosine kinase inhibitors - a review on pharmacology, metabolism and side effects. Curr Drug Metab. 2009;10:470-481.

11. Webster-Gandy JD, How C, Harrold K. Palmar-plantar erythrodysesthesia (PPE): a literature review with commentary on experience in a cancer centre. Eur J Oncol Nurs. 2007;11:238-246.
12. Kumar S, Juresic E, Barton M, Shafiq J. Management of skin toxicity during radiation therapy: a review of the evidence. J Med Imaging Radiat Oncol. 2010;54:264-279.

13. Haley AC, Calahan C, Gandhi M, West DP, Rademaker A, Lacouture ME. Skin care management in cancer patients: an evaluation of quality of life and tolerability. Support Care Cancer. 2011;19:545-554.

14. MASCC: Caring for your skin, hait and nails whenon "targeted therapies", 2011. Available from: (http://www.mascc.org/assets/documents/skin_toxicity_egfri_patientbrochure.pdf). Accessed April 10, 2014.

15. American Cancer Society: Targeted therapy, 2013. Available from:(http:// www.cancer.org/acs/groups/cid/documents/webcontent/003024-pdf. pdf). Accessed April 10, 2014.

16. Dreno B, Bensadoun RJ, Humbert P, et al. Algorithm for dermocosmetic use in the management of cutaneous side-effects associated with targeted therapy in oncology. J Eur Acad Dermatol Venereol. 2013;27: 1071-1080.

17. Potthoff K, Hofheinz R, Hassel JC, et al. Interdisciplinary management of EGFR-inhibitor-induced skin reactions: a German expert opinion. Ann Oncol. 2011;22:524-535.

18. Patrizi A, Venturi M, Dika E, Maibach H, Tacchetti P, Brandi G. Cutaneous adverse reactions linked to targeted anticancer therapies bortezomib and lenalidomide for multiple myeloma: new drugs, old side effects. Cutan Ocul Toxicol. 2014;33:1-6.

19. Mateus C, Robert C. New drugs in oncology and skin toxicity. Rev Med Interne. 2009;30:401-410. French.

20. Lacouture ME, Melosky BL. Cutaneous reactions to anticancer agents targeting the epidermal growth factor receptor: a dermatology-oncology perspective. Skin Therapy Lett. 2007;12:1-5.

21. Galimont-Collen AF, Vos LE, Lavrijsen AP, Ouwerkerk J, Gelderblom H. Classification and management of skin, hair, nail and mucosal side-effects of epidermal growth factor receptor (EGFR) inhibitors. Eur J Cancer. 2007;43:845-851.

22. Lacouture ME, Anadkat MJ, Bensadoun RJ, et al. Clinical practice guidelines for the prevention and treatment of EGFR inhibitorassociated dermatologic toxicities. Support Care Cancer. 2011;19: 1079-1095.

23. Agha R, Kinahan K, Bennett CL, Lacouture ME. Dermatologic challenges in cancer patients and survivors. Oncology (Williston Park). 2007;21:1462-1472; discussion 1473, 1476, 1481 passim.

24. Zhang Z, Riviere JE, Monteiro-Riviere NA. Evaluation of protective effects of sodium thiosulfate, cysteine, niacinamide and indomethacin on sulfur mustard-treated isolated perfused porcine skin. Chem Biol Interact. 1995;96:249-262.

25. Namazi MR. Nicotinamide in dermatology: a capsule summary. Int $J$ Dermatol. 2007;46:1229-1231.

26. Bissett D. Topical niacinamide and barrier enhancement. Cutis. 2002;70:8-12; discussion 21-23.

27. Gehring W. Nicotinic acid/niacinamide and the skin. JCosmet Dermatol. 2004;3:88-93

28. Otte N, Borelli C, Korting HC. Nicotinamide - biologic actions of an emerging cosmetic ingredient. Int J Cosmet Sci. 2005;27:255-261.

29. Tanno O, Ota Y, Kitamura N, Katsube T, Inoue S. Nicotinamide increases biosynthesis of ceramides as well as other stratum corneum lipids to improve the epidermal permeability barrier. $\mathrm{Br} J$ Dermatol. 2000;143:524-531.

30. Dharajiya N, Choudhury BK, Bacsi A, Boldogh I, Alam R, Sur S. Inhibiting pollen reduced nicotinamide adenine dinucleotide phosphate oxidase-induced signal by intrapulmonary administration of antioxidants blocks allergic airway inflammation. J Allergy Clin Immunol. 2007;119:646-653.

31. White SD, Rosychuk RA, Reinke SI, Paradis M. Use of tetracycline and niacinamide for treatment of autoimmune skin disease in $31 \mathrm{dogs}$. J Am Vet Med Assoc. 1992;200:1497-1500.

32. Fabbrocini G, Cantelli M, Monfrecola G. Topical nicotinamide for seborrheic dermatitis: an open randomized study. J Dermatolog Treat. 2014;25:241-245.

33. Namazi MR. Nicotinamide as a potential addition to the anti-atopic dermatitis armamentarium. Int Immunopharmacol. 2004;4(6):709-712. 
34. Cosmetic Ingredient review expert panel. Final report of safety assessment of niacinamide and niacin. Int J Toxicol. 2005;24 Suppl 5:1-31.

35. Finlay AY, Khan GK. Dermatology Life Quality Index (DLQI) a simple practical measure for routine clinical use. Clin Exp Dermatol. 1994;19:210-216.

36. Lewis V, Finlay AY. 10 years experience of the Dermatology Life Quality Index (DLQI). J Investig Dermatol Symp Proc. 2004;9:169-180.

37. Nijsten T, Meads DM, McKenna SP. Dimensionality of the dermatology life quality index (DLQI): a commentary. Acta Derm Venereol. 2006;86:284-285; author reply 285-286.

38. Finlay AY, Basra MK, Piguet V, Salek MS. Dermatology life quality index (DLQI): a paradigm shift to patient-centered outcomes. J Invest Dermatol. 2012;132:2464-2465.

39. Hongbo Y, Thomas CL, Harrison MA, Salek MS, Finlay AY. Translating the science of quality of life into practice: What do dermatology life quality index scores mean? J Invest Dermatol. 2005;125: 659-664.

40. Basra MK, Fenech R, Gatt RM, Salek MS, Finlay AY. The Dermatology Life Quality Index 1994-2007: a comprehensive review of validation data and clinical results. Br J Dermatol. 2008;159: 997-1035

41. Craig BM, Busschbach JJ, Salomon JA. Modeling ranking, time tradeoff, and visual analog scale values for EQ-5D health states: a review and comparison of methods. Med Care. 2009;47:634-641.

42. Namazi MR. Nicotinamide-containing sunscreens for use in Australasian countries and cancer-provoking conditions. Med Hypotheses. 2003;60:544-545.

43. Surjana D, Halliday GM, Damian DL. Nicotinamide enhances repair of ultraviolet radiation-induced DNA damage in human keratinocytes and ex vivo skin. Carcinogenesis. 2013;34:1144-1149.

44. Gupta N, Saleem A, Kotz B, Kötz B. Carbogen and nicotinamide increase blood flow and 5-fluorouracil delivery but not 5-fluorouracil retention in colorectal cancer metastases in patients. Clin Cancer Res. 2006;12:3115-3123.
45. Grange PA, Raingeaud J, Calvez V, Dupin N. Nicotinamide inhibits Propionibacterium acnes-induced IL- 8 production in keratinocytes through the NF-kappaB and MAPK pathways. J Dermatol Sci. 2009;56: 106-112.

46. Monfrecola G, Gaudiello F, Cirillo T, Fabbrocini G, Balato A, Lembo S. Nicotinamide downregulates gene expression of interleukin-6, interleukin-10, monocyte chemoattractant protein-1, and tumour necrosis factor-alpha gene expression in $\mathrm{HaCaT}$ keratinocytes after ultraviolet B irradiation. Clin Exp Dermatol. 2013;38:185-188.

47. Cosmetic Ingredient Review Expert Panel. Final report of the safety assessment of niacinamide and niacin. Int J Toxicol. 2005;24 Suppl 5: $1-31$.

48. Knip M, Douek IF, Moore WP, et al. Safety of high-dose nicotinamide: a review. Diabetologia. 2000;43:1337-1345.

49. Vasantha J, Soundararajan P, Vanitharani N, et al. Safety and efficacy of nicotinamide in the management of hyperphosphatemia in patients on hemodialysis. Indian J Nephrol. 2011;21:245-249.

50. Pigott K, Dische S, Saunders MI. Short communication: the addition of carbogen and nicotinamide to a palliative fractionation schedule for locally advanced breast cancer. Br J Radiol. 1995;68:215-218.

51. Ruddock MW, Hirst DG. Nicotinamide relaxes vascular smooth muscle by inhibiting myosin light chain kinase-dependent signaling pathways: implications for anticancer efficacy. Oncol Res. 2004;14:483-489.

52. Hoesly FJ, Baker SG, Gunawardane ND, Cotliar JA. Capecitabineinduced hand-foot syndrome complicated by pseudomonal superinfection resulting in bacterial sepsis and death: case report and review of the literature. Arch Dermatol. 2011;147:1418-1423.

53. Khandanpour C, Dührsen U, Röth A. Hand-Foot syndrome: Common presentation in an uncommon situation. Eur J Haematol. 2013;91:472.

54. Yokomichi N, Nagasawa T, Coler-Reilly A, et al. Pathogenesis of HandFoot Syndrome induced by PEG-modified liposomal Doxorubicin. Hum Cell. 2013;26:8-18.
Breast Cancer: Targets and Therapy

\section{Publish your work in this journal}

Breast Cancer: Targets and Therapy is an international, peerreviewed open access journal focusing on breast cancer research, identification of therapeutic targets and the optimal use of preventative and integrated treatment interventions to achieve improved outcomes, enhanced survival and quality of life for the cancer patient.

\section{Dovepress}

View the full aims and scopes of this journal here. The manuscript management system is completely online and includes a very quick and fair peer-review system, which is all easy to use. Visit http:// www.dovepress.com/testimonials.php to read real quotes from published authors. 